\title{
Parental preference and perspectives on continuous pulse oximetry in infants and children with bronchiolitis
}

This article was published in the following Dove Press journal:

Patient Preference and Adherence

\author{
Mohamed A Hendaus ${ }^{1,2}$ \\ Suzan Nassar ${ }^{3}$ \\ Bassil A Leghrouz ${ }^{3}$ \\ Ahmed H Alhammadi ${ }^{1,2}$ \\ Mohammed Alamri ${ }^{4}$ \\ 'Department of Pediatrics, Section of \\ Academic General Pediatrics, Sidra \\ Medicine, Doha, Qatar; ${ }^{2}$ Department \\ of Clinical Pediatrics, Weill Cornell \\ Medicine, Doha, Qatar; ${ }^{3}$ Department \\ of Pediatrics, Hamad General \\ Corporation, Doha, Qatar; ${ }^{4}$ Pediatric \\ Emergency Center, Hamad General \\ Corporation, Doha, Qatar
}

Objective: The purpose of the study was to investigate parental preference of continuous pulse oximetry in infants and children with bronchiolitis.

Materials and methods: A cross-sectional prospective study was conducted at Hamad Medical Corporation in Qatar. Parents of infants and children $<24$ months old and hospitalized with bronchiolitis were offered an interview survey.

Results: A total of 132 questionnaires were completed (response rate 100\%). Approximately $90 \%$ of participants were $20-40$ years of age, and $85 \%$ were females. The mean age of children was $7.2 \pm 5.8$ months. Approximately eight in ten parents supported the idea of continuous pulse oximetry in children with bronchiolitis. Almost $43 \%$ of parents believed that continuous pulseoximetry monitoring would delay their children's hospital discharge. Interestingly, approximately $85 \%$ of caregivers agreed that continuous pulse oximetry had a good impact on their children's health. In addition, around one in two of the participants stated that good bedside examinations can obviate the need for continuous pulse oximetry. Furthermore, $80 \%$ of parents believed that continuous pulse-oximetry monitoring would give the health-care provider a good sense of security regarding the child's health. Finally, being a male parent was associated with significantly increased risk of reporting unnecessary fatigue, attributed to the sound of continuous pulse oximetry $(P=0.031)$.

Conclusion: Continuous pulse-oximetry monitoring in children with bronchiolitis was perceived as reassuring for parents. Involving parents in decision-making is considered essential in the better management of children with bronchiolitis or any other disease. The first step to decrease continuous pulse oximetry will require provider education and change as well. Furthermore, we recommend proper counseling for parents, emphasizing that medical technology is not always essential, but is a complementary mode of managing a disease.

Keywords: bronchiolitis, parents, medical, technology

\section{Introduction}

Bronchiolitis is a respiratory disorder typically produced by viral lower respiratory tract infection in infants and young children. The pathophysiology of bronchiolitis begins with acute inflammation, ensuing edema, and mucus production. ${ }^{1}$ The pillar of bronchiolitis management is supportive care, with good proof that most treatments are futile, including antibiotics, bronchodilators, and corticosteroids. ${ }^{1}$ However, considerable variability continues in the care for patients with bronchiolitis, possibly resulting in unnecessary and expensive use of resources. ${ }^{2}$ In this era, young children with acute bronchiolitis admitted to health-care centers are often overseen with pulse oximetry, ${ }^{3}$ a noninvasive technique usually used for measuring oxygen saturation. ${ }^{4}$
Correspondence: Mohamed A Hendaus Department of Pediatrics, Sidra Medicine, Al Al Luqta Street, PO BOX 26999.

Doha, Qatar

Tel +97440036559

Fax +974 4443 957I

Emailmhendaus@yahoo.com 
The determination to hospitalize children with bronchiolitis has been vastly impacted by pulse oximetry, in spite of its dubious diagnostic importance in delineating the severity of the illness. ${ }^{5}$ A large number of clinicians have deficits in the clinical fundamentals and constraints of pulse oximetry, ${ }^{4,6}$ and their judgments to hospitalize the infant might be based on only a $2 \%$ difference in oxygen saturation. ${ }^{7}$ Although it leads to feeble prognostication of respiratory distress, oxygen saturation is associated strongly with an increased proportion of hospitalization of young children with acute bronchiolitis $^{8}$ and an influence on hospital length of stay. ${ }^{9,10}$ The purpose of this study was to investigate parental preference with regard to continuous pulse oximetry in infants and children with bronchiolitis, as there are no data or studies that outline such choice.

\section{Materials and methods Study design, period, setting, and participants}

A cross-sectional prospective investigation through an interview survey was administered in the general pediatric ward at Hamad Medical Corporation (HMC), the only tertiary care and academic institution in Qatar. Ethical approval for this study was obtained from the Hamad Medical Corporation Ethics Committee (15456/15).

Hamad Medical Corporation is a very well-resourced institution where most hospitalized infants and children with respiratory conditions are attached to continuous pulse oximetry. Patients with bronchiolitis are admitted to the pediatric ward for observation, enteral feeding, and fluid supplementation. Parents of hospitalized children aged $\leq 2$ years with mild-moderate bronchiolitis and no oxygen requirement were offered an interview. Caregivers were approached at the bedside while their children still in the pediatric ward. We excluded all children requiring oxygen, patients with severe bronchiolitis, and intensive care-unit cases. The definition and the severity of bronchiolitis was adopted from the American Academy of Pediatrics. ${ }^{1}$ We also excluded children requiring oxygen related to disorders other than bronchiolitis, such as cardiac disease and chronic lung disease.

Participants were approached at the bedside where their children were. The study took place between January 11, 2016 and April 4, 2016. There are no data in Qatar to calculate sample size. In addition, there are no identical published studies to extrapolate the correct number of patients needed, so a convenience sample was chosen. Verbal informed consent was obtained at the time of the interview, and all materials were available in English and Arabic. In a few encounters $(n=9)$, the nurses assisted us in translating from Urdu, Hindi, and Pashto.

Parents were informed as to why the information was being gathered and how it would be utilized. Before parents filled in the questionnaire, a statement was read to them informing them that their input was voluntary, and we assured them that their responses were confidential and anonymous. Participants did not get any type of remuneration for being involved in the study. This study was approved by the Hamad Medical Corporation Medical Research Center.

We used an anonymous modified interview-based assessment with data obtained from published studies, ${ }^{3,11-15}$ and modified it to meet our parental culture. The Medical Research Center in our organization validated the questionnaire, which comprised of a total of 14 items. The questions addressed parent and child demographics, as well as questions related to parental preference of continuous pulseoximetry monitoring in mild-moderate bronchiolitis, the role of physical exams, and fatigue related to the sound of the pulse-oximetry apparatus.

\section{Statistical analysis}

Quantitative data values are displayed as frequencies with percentages and means \pm standard deviation. Descriptive statistics were applied to curtail demographic and all additional features of the participants. Significance between two or more qualitative or categorical variables was assessed using $\chi^{2}$ testing. Graphic presentations are used to integrate the display of results. A two-sided $P$-value $<0.05$ was statistically significant. All statistical analyses were handled using SPSS version 19.0 (IBM, Armonk, NY, USA).

\section{Results}

A total of 132 questionnaires were completed (response rate $100 \%)$. Approximately $90 \%(n=118)$ of participants were 20-40 years of age, and $85 \%(n=112)$ were females. A summary of demographic characteristics is given in Table 1. The mean age of the children was $7.2 \pm 5.8$ months, and almost half $45 \%(n=60)$ had previously been admitted to the hospital with a diagnosis of simple bronchiolitis. Approximately $77 \%$ $(n=102)$ of parents supported the idea of continuous pulse oximetry in children with bronchiolitis.

Almost $42 \%(n=56)$ of parents believed that continuous pulse-oximetry monitoring would delay their children's hospital discharge. Interestingly, approximately $83 \%(n=110)$ of caregivers agreed that continuous pulse oximetry had a good impact on their children's health. In addition, around $48 \%$ $(n=64)$ of participants stated that good bedside examination 
Table I Demographic characteristics of participants

\begin{tabular}{ll}
\hline & $\mathbf{n}(\%)$ \\
\hline Parent sex & \\
Male & $20(15.2)$ \\
Female & $112(84.8)$ \\
Parent age (years) & \\
$<20$ & $7(5.3)$ \\
$20-29$ & $63(47.7)$ \\
$30-39$ & $55(41.7)$ \\
$\geq 40$ & $7(5.3)$ \\
Parental education & \\
Less than high school & $23(17.4)$ \\
High school & $45(34.1)$ \\
Some college & $18(13.6)$ \\
College graduate & $38(28.8)$ \\
Postgraduate & $8(6.1)$ \\
Parent working in the health-care field & \\
Yes & $13(10)$ \\
No & $119(90)$ \\
Child sex & \\
Male & $78(59.1)$ \\
Female & \\
Child age-group (months) & \\
$<2$ & $54(40.9)$ \\
$\geq 2$ & $24(18.5)$ \\
\hline
\end{tabular}

can obviate the need for continuous pulse oximetry. Furthermore, $80 \%(\mathrm{n}=105)$ of parents believed that continuous pulse-oximetry monitoring would give the health-care provider a good sense of security regarding the child's health (Figure 1). Despite all of this, $57 \%(n=75)$ conveyed that the sound of continuous pulse-oximetry alarms incited unnecessary fatigue in parents.
It is worth mentioning that parental age ( $>20$ years) was associated with the belief that continuous pulse-oximetry monitoring would have a good impact on their children's condition $(P=0.045)$, and parental sex (male) was linked to the belief that the monitoring provided a good sense of security regarding the child's health $(P=0.043)$. Finally, being a male parent was associated with significantly increased risk of reporting unnecessary fatigue attributed to the sound of continuous pulse oximetry $(P=0.031)$. The remaining associations among sociodemographic factors, such as level of education and health-care work experience, and questions related to the perception of parents toward continuous pulse oximetry in bronchiolitis were not statistically significant $(P>0.05)$.

\section{Discussion}

Our study has shown that parents of infants and children hospitalized with bronchiolitis prefer continuous pulse oximetry to monitor their offspring's condition. This is the first study to explore parental preference and perspectives in such acute disease. Parents were predominantly satisfied with continuous pulse-oximetry monitoring, perceiving it as an important and valued device to keep children safe. This perception does not second the American Academy of Pediatrics recommendation of clinical assessment for diagnosis and management of bronchiolitis. ${ }^{1}$ Although it is considered a weak prognostic factor in respiratory distress, oxygen saturation is associated with a hike in the rate of hospitalization ${ }^{8}$ and prolongation of the length of stay of young children in hospital with acute bronchiolitis. ${ }^{8-10}$

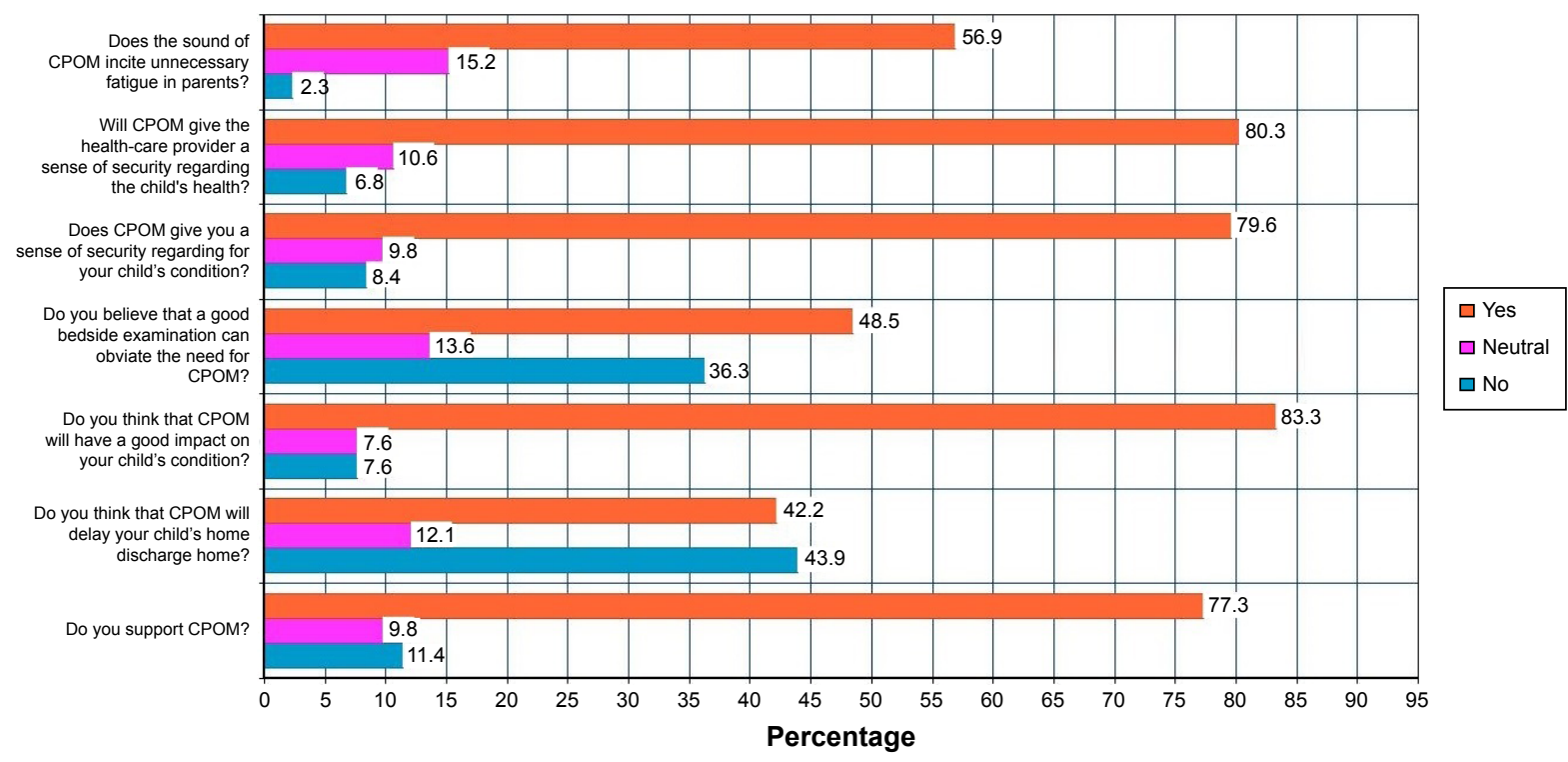

Figure I Answers related to parental pulse-oximetry preference. Abbreviation: CPOM, continuous pulse-oximetry monitoring. 
There is no accord regarding the oxygen-saturation threshold for the initiation of oxygen supplements in children with bronchiolitis. ${ }^{16,17}$ In practice, physician preference also seems to be toward pulse oximetry and that we use it to make decisions without evidence behind it. The link between oxygen saturation and respiratory distress in young children with respiratory infections has not been proved conclusively. ${ }^{18,19}$ Furthermore, children can have physiologic low oxygen saturation during sleep, particularly those residing at high altitudes. ${ }^{20}$

In addition to its questionable use in bronchiolitis, frequent alarms from pulse oximetry due to erroneous assessment in an active child or infant might result in alarm fatigue. ${ }^{21}$ This tiredness has been linked to alarming safety situations, ${ }^{22,23}$ where physicians, nurses, or respiratory therapists might decrease the volume of the alarm or even turn it off, which can lead to dangerous results. ${ }^{12}$

Studies in pediatrics have reported that parents are willing to be involved in management decisions, and this participation may affect both the consequences of care and parent satisfaction. ${ }^{24-27}$ The literature has shown that parents are willing to share in medical decisions as long as they are provided with support and information to guide them. ${ }^{28}$ Involving parents in decision-making in regard to their children's health augments satisfaction and leads to improved adherence with plans discussed. ${ }^{29}$ With both medical proof and personal values defined, the health-care provider and family can jointly decide the treatment plan. ${ }^{30}$ In spite of the disparity in medical knowledge between health-care providers and laypersons, patients can determine specific interventions they deem essential. ${ }^{31,32}$ Moreover, health-related fear influences when wanted diagnostic interventions are not acknowledged. ${ }^{33}$ Health-care providers may be able to handle such attachments of patient to technology by inquiring about parents' fears and testing the suitability of suggested clinical strategies. ${ }^{34}$ Such inquiring and good communication skills have a positive impact on patient satisfaction and treatment devotion. Studies have shown that this type of communication and patient involvement can be taught effectively during medical training. ${ }^{35}$ This study delivers data for future research, and could be used in creation of better rapport between healthcare providers and parents.

This study has several strengths, specifically both the quantitative and qualitative responses. Our study will assist in illustrating the need for parental education and involvement in the decision-making process when it comes to pulseoximetry use. This study also has limitations. We used a convenience sample. The limitations to external validity are mainly due to a very novice concept. Moreover, there might be a chance that there are specific characteristics related to parental preference in this topic that were not assessed in this study. In addition, our patients were already on continuous pulse oximetry, which is a confounding factor when asking whether caregivers think that it is important or necessary. Finally, possible transcultural factors were an issue in counting on continuous pulse oximetry. We were not able to assess this type of possible confounder, as residents of Qatar are a blend from almost every country in the world.

\section{Conclusion}

Continuous pulse-oximetry monitoring in children with bronchiolitis was perceived as reassuring for parents. Involving parents in decision-making is considered essential in the better management of children with bronchiolitis or any other disease. The first step to decrease continuous pulse oximetry will require provider education and change as well. Furthermore, we recommend proper counseling for parents, emphasizing that medical technology is not always essential, but a complementary mode of managing a disease.

\section{Acknowledgments}

The authors would like to thank the Medical Research Center in Hamad Medical Corporation for their support and ethical approval. The study was presented at the American Academy of Pediatrics National Conference and Exhibition as a poster presentation with interim findings, held in San Francisco, USA on October 26, 2016.

\section{Disclosure}

The authors report no conflicts of interest in this work.

\section{References}

1. Ralston SL, Lieberthal AS, Meissner HC, et al. Clinical practice guideline: the diagnosis, management, and prevention of bronchiolitis. Pediatrics. 2014;134(5):e1474-e1502.

2. Parikh K, Hall M, Teach SJ. Bronchiolitis management before and after the AAP guidelines. Pediatrics. 2014;133(1):e1-e7.

3. Schroeder AR, Marmor AK, Pantell RH, Newman TB. Impact of pulse oximetry and oxygen therapy on length of stay in bronchiolitis hospitalizations. Arch Pediatr Adolesc Med. 2004;158(6):527-530.

4. Fouzas S, Priftis KN, Anthracopoulos MB. Pulse oximetry in pediatric practice. Pediatrics. 2011;128(4):740-752.

5. Hendaus MA, Jomha FA, Alhammadi AH. Pulse oximetry in bronchiolitis: is it needed? Ther Clin Risk Manag. 2015;11:1573-1578.

6. Elliott M, Tate R, Page K. Do clinicians know how to use pulse oximetry? A literature review and clinical implications. Aust Crit Care. 2006;19(4):139-144.

7. Mallory MD, Shay DK, Garrett J, Bordley WC. Bronchiolitis management preferences and the influence of pulse oximetry and respiratory rate on the decision to admit. Pediatrics. 2003;111(1):e45-e51.

8. Corneli HM, Zorc JJ, Holubkov R, et al. Bronchiolitis: clinical characteristics associated with hospitalization and length of stay. Pediatr Emerg Care. 2012;28(2):99-103. 
9. Cunningham S, McMurray A. Observational study of two oxygen saturation targets for discharge in bronchiolitis. Arch Dis Child. 2012; 97(4):361-363.

10. Unger S, Cunningham S. Effect of oxygen supplementation on length of stay for infants hospitalized with acute viral bronchiolitis. Pediatrics. 2008;121(3):470-475.

11. Schondelmeyer AC, Simmons JM, Statile AM, et al. Using quality improvement to reduce continuous pulse oximetry use in children with wheezing. Pediatrics. 2015;135(4):e1044-e1051.

12. Joint Commission on Accreditation of Healthcare Organizations. The Joint Commission announces 2014 National Patient Safety Goal. Jt Comm Perspect. 2013;33(7):1-4.

13. Martin S, Martin J, Seigler T. Evidence-based protocols to guide pulse oximetry and oxygen weaning in inpatient children with asthma and bronchiolitis: a pilot project. J Pediatr Nurs. 2015;30(6):888-895.

14. Powell R, Pattison HM, Bhoyar A, et al. Pulse oximetry screening for congenital heart defects in newborn infants: an evaluation of acceptability to mothers. Arch Dis Child Fetal Neonatal Ed. 2013;98(1): F59-F63.

15. Ewer AK, Furmston AT, Middleton LJ, et al. Pulse oximetry as a screening test for congenital heart defects in newborn infants: a test accuracy study with evaluation of acceptability and cost-effectiveness. Health Technol Assess. 2012;16(2):v-xiii, 1-184.

16. Zorc JJ, Hall CB. Bronchiolitis: recent evidence on diagnosis and management. Pediatrics. 2010;125(2):342-349.

17. American Academy of Pediatrics Subcommittee on Diagnosis and Management of Bronchiolitis. Diagnosis and management of bronchiolitis. Pediatrics. 2006;118(4):1774-1793.

18. Pope J, McBride J. Consultation with the specialist: respiratory failure in children. Pediatr Rev. 2004;25(5):160-167.

19. Kim V, Benditt JO, Wise RA, Sharafkhaneh A. Oxygen therapy in chronic obstructive pulmonary disease. Proc Am Thorac Soc. 2008;5(4): 513-518.

20. Gavlak JC, Stocks J, Laverty A, et al. The Young Everest Study: preliminary report of changes in sleep and cerebral blood flow velocity during slow ascent to altitude in unacclimatised children. Arch Dis Child. 2013;98(5):356-362.

21. Lutter NO, Urankar S, Kroeber S. False alarm rates of three thirdgeneration pulse oximeters in PACU, ICU and IABP patients. Anesth Analg. 2002;94(1 Suppl):S69-S75.
22. Keesler J. The dangers of alarm fatigue. Nurs Manage. 2014;45(4): 8,10 .

23. Ulrich B. Alarm fatigue: a growing problem. Nephrol Nurs J. 2013; 40(4):293, 346.

24. Lewis CC, Pantell RH, Sharp L. Increasing patient knowledge, satisfaction, and involvement: randomized trial of a communication intervention. Pediatrics. 1991;88(2):351-358.

25. Merenstein D, Diener-West M, Krist A, Pinneger M, Cooper LA. An assessment of the shared-decision model in parents of children with acute otitis media. Pediatrics. 2005;116(6):1267-1275.

26. Wissow LS, Gadomski A, Roter D, et al. Improving child and parent mental health in primary care: a cluster-randomized trial of communication skills training. Pediatrics. 2008;121(2):266-275.

27. McWilliams DB, Jacobson RM, van Houten HK, Naessens JM, Ytterberg KL. A program of anticipatory guidance for the prevention of emergency department visits for ear pain. Arch Pediatr Adolesc Med. 2008;162(2):151-156.

28. Jackson C, Cheater FM, Reid I. A systematic review of decision support needs of parents making child health decisions. Health Expect. 2008;11(3):232-251.

29. Fiks AG, Localio AR, Alessandrini EA, Asch DA, Guevara JP. Shared decision-making in pediatrics: a national perspective. Pediatrics. 2010; 126(2):306-314.

30. Fiks AG, Jimenez ME. The promise of shared decision-making in paediatrics. Acta Paediatr. 2010;99(10):1464-1466.

31. Joos SK, Hickam DH, Borders LM. Patients' desires and satisfaction in general medicine clinics. Public Health Rep. 1993;108(6):751-759.

32. Kravitz RL, Cope DW, Bhrany V, Leake B. Internal medicine patients' expectations for care during office visits. J Gen Intern Med. 1994; 9(2):75-81.

33. Sox HC, Marguiles I, Sox CH. Psychologically mediated effects of diagnostic tests. Ann Intern Med. 1981;95(6):680-685.

34. Kravitz RL, Callahan EJ. Patients' perceptions of omitted examinations and tests: a qualitative analysis. J Gen Intern Med. 2000;15(1): $38-45$.

35. Levinson W, Lesser CS, Epstein RM. Developing physician communication skills for patient-centered care. Health Aff (Millwood). 2010 29(7):1310-1318.
Patient Preference and Adherence

\section{Publish your work in this journal}

Patient Preference and Adherence is an international, peer-reviewed, open access journal that focuses on the growing importance of patient preference and adherence throughout the therapeutic continuum. Patient satisfaction, acceptability, quality of life, compliance, persistence and their role in developing new therapeutic modalities and compounds to optimize

\section{Dovepress}

clinical outcomes for existing disease states are major areas of interest for the journal. This journal has been accepted for indexing on PubMed Central. The manuscript management system is completely online and includes a very quick and fair peer-review system, which is all easy to use. Visit http://www. dovepress.com/testimonials.php to read real quotes from published authors. 